\title{
The Role of Models in Prediction for Decision
}

ROGER A. PIELKE JR.

\begin{abstract}
Summary
The processes of science and decision making share an important characteristic: success in each depends upon researchers or decision makers having some ability to anticipate the consequences of their actions. The predictive capacity of science holds great appeal for decision makers who are grappling with complex and controversial environmental issues by promising to enhance their ability to determine a need for and outcomes of alternative decisions. As a result, the very process of science can be portrayed as a positive step toward solving a policy problem. The convergence-and perhaps confusion - of prediction in science and prediction for policy presents a suite of hidden dangers for the conduct of science and the challenge of effective decision making. This chapter, organized as a set of inter-related analytical vignettes, seeks to expose some of these hidden dangers and to recommend strategies to overcome them in the process of environmental decision making. In particular, this chapter will try to distill some of the lessons gleaned from research on modeling, prediction, and decision making in the earth and atmospheric sciences for quantitative modeling of ecosystems. One clear implication is that conventional approaches to modeling and prediction cannot simultaneously meet the needs of both science and decision making. For ecosystem science, there fortunately exists a body of experience in understanding, using, and producing predictions across the sciences on which to develop new understandings of the relationship of science and decision making to the potential benefit of both research and policy.
\end{abstract}




\section{Introduction: Prediction in Science and Prediction for Decision}

The processes of science and decision making share an important characteristic: success in each depends upon researchers or decision makers having some ability to anticipate the consequences of their actions. On the one hand, "[being] predictive of unknown facts is essential to the process of empirical testing of hypotheses, the most distinctive feature of the scientific enterprise" (Ayala 1996). Of course, in science the "unknown facts" in question could lie in the past or the future. "Decision-making," on the other hand, "is forward looking, formulating alternative courses of action extending into the future, and selecting among alternatives by expectations of how things will turn out" (Lasswell and Kaplan 1950).

The predictive capacity of science holds great appeal for decision makers who are grappling with complex and controversial environmental issues because it promises to enhance their ability to determine a need for and outcomes of alternative decisions. As a result, the very process of science can be portrayed as a positive step toward solving a policy problem. The appeal of this "two birds with one stone" line of reasoning is obvious for decision makers who would place the onus of responsibility for problem solving onto the shoulders of scientists. But this reasoning is also seductive for scientists who might wish to better justify public investments in research, as well as for a public that has come to expect solutions because of such investments (Sarewitz and Pielke 1999).

The convergence - and perhaps confusion - of prediction in science and prediction for policy presents a suite of hidden dangers for the conduct of science and the challenge of effective decision making. This paper, organized as a set of interrelated analytical vignettes, seeks to expose some of these hidden dangers and to recommend strategies to overcome them in the process of environmental decision making. In particular, this paper seeks to distill some of the lessons gleaned from research on modeling, prediction, and decision making in the earth and atmospheric sciences for quantitative modeling of ecosystems, the focus of Cary Conference IX. The background materials for the conference noted that "recent years have seen dramatic advancements in the computational power and mathematical tools available to modelers. Methodological advances in areas ranging from remote sensing to molecular techniques have significantly improved our ability to parameterize and validate models at a wide range of spatial scales. The body of traditional, mechanistic, empirical research is also growing phenomenally. Ecosystem science is ripe for major gains in the synthetic and predictive power of its models, and that this comes at a time of growing need by society for quantitative models that can inform debate about critical environmental issues."

This background indicates that the community of ecosystem scientists is following other fields - particularly the atmospheric, oceanic, and earth sciencesdown a path of using integrative environmental modeling to advance science 
and to generate predictive knowledge putatively to inform decision making (Clark et al. 2001). This paper distills some of the most important lessons from the other fields that have journeyed down this perilous path, focusing on the use of models to produce predictions for decision.

\section{Modeling for What?}

Bankes (1993) defines two types of quantitative models, consolidative and exploratory, that are differentiated by their uses (cf. Morrison and Morgan 1999). A consolidative model seeks to include all relevant facts into a single package and use the resulting system as a surrogate for the actual system. The canonical example is that of the controlled laboratory experiment. Other examples include weather forecasting and engineering design models. Such models are particularly relevant to decision making because the system being modeled can be treated as being closed. Oreskes et al. (1994) define a closed system as one "in which all the components of the system are established independently and are known to be correct" (Oreskes et al. 1994). ${ }^{1}$ The creation of such a model generally follows two phases: first, model construction and evaluation; and second, operational usage of a final product. Such models can be used to investigate diagnostics (i.e., What happened?), process (Why did it happen?), or prediction (What will happen?).

An exploratory model — or what Bankes (1993) calls a "prosthesis for the intellect"-is one in which all components of the system being modeled are not established independently or are not known to be correct. In such a case, the model allows for experiments with the model to investigate the consequences for modeled outcomes of various assumptions, hypotheses, and uncertainties associated with the creation of and inputs to the model. These experiments can contribute to at least three important functions (Bankes 1993). First, they can shed light on the existence of unexpected properties associated with the interaction of basic assumptions and processes (e.g., complexity or surprises). Second, in cases where explanatory knowledge is lacking, exploratory models can facilitate hypothesis generation to stimulate further investigation. Third, the model can be used to identify limiting, worst-case, or special scenarios under various assumptions and uncertainty associated with the model experiment. Such experiments can be motivated by observational data (e.g., econometric and hydrologic models), by scientific hypotheses (e.g., general circulation models of climate), or by a desire to understand the properties of the model or class of models independent of real-world data or hypotheses (e.g., Lovelock's Daisyworld).

Both consolidative and exploratory models have important roles to play in science and decision settings (Bankes 1993). However, the distinction between consolidative and exploratory modeling is fundamental but rarely made in practice or in interpretation of research results. Often, the distinction is implicitly (or explicitly) blurred to "kill two birds with one stone" in modeling and pre- 
dicting for science and policy (Sarewitz and Pielke 1999). ${ }^{2}$ Consider, for example, the goal of the U.S. Global Change Research Program, from 1989: "To gain an adequate predictive understanding of the interactive physical, geological, chemical, biological and social processes that regulate the total Earth System and, hence establish the scientific basis for national and international policy formulation and decisions" (CES 1989, 9). ${ }^{3}$

And following from this conflation, most presentations by scientists and the media of the results of national and international climate assessments have sought to imbue the imprimatur of consolidative knowledge upon what are inherently exploratory exercises. ${ }^{4}$ Those who conflate the science and policy roles of prediction and modeling trade short-term political or public gain with a substantial risk of a more lasting loss of legitimacy and political effectiveness (Sarewitz et al. 2000).

Thus, one of the most important lessons to be learned from the experiences of other scientific endeavors in which modeling has a potential role to play in research and decision is that one must be clear about the purposes for which the modeling is to be used and carefully examine any assumption that presumes isomorphism between the needs of science and the needs of decision making.

\section{Importance of Uncertainty}

Uncertainty, in the view of economist John Maynard Keynes, is the condition of all human life (Skidelsky 2000). Uncertainty means that more than one outcome is consistent with our expectations (Pielke 2001). Expectations are a result of judgment, are sometimes based on technical mistakes and interpretive errors, and are shaped by values and interests. As such, uncertainty is not some feature of the natural world waiting to be revealed but is instead a fundamental characteristic of how human perceptions and understandings shape expectations. Because uncertainty is a characteristic of every important decision, it is no surprise that society looks to science and technology to help clarify our expectations in ways that lead to desired outcomes.

Because decision making is forward-looking, decision makers have traditionally supported research to quantify and even reduce uncertainties about the future. In many cases, particularly those associated with closed systems - or systems that can be treated as closed - understanding uncertainty is a straightforward technical exercise: probabilities in a card game are the canonical example. Two real-world examples include error analysis in engineering and manufacturing, and the actuarial science that underlies many forms of insurance. However, in many other circumstances - particularly those associated with human action-systems are intrinsically open and cannot be treated as closed, meaning that understanding uncertainty is considerably more challenging. In recent decades, many scientists have taken on the challenge of understanding such open systems (e.g., global climate, genetic engineering, etc.), and 
in the process of securing considerable public resources to pursue this challenge, scientists often explicitly promise to "understand and reduce uncertainties" as input to important societal decisions.

Conventional wisdom holds that uncertainty is best understood or reduced by advancing knowledge, an apparent restatement of the traditional definition of uncertainty as "incomplete knowledge" (Cullen and Small 2000). But in reality, advances in knowledge can add significant uncertainty. For example, in 1990 the Intergovernmental Panel on Climate Change (IPCC) projected a $1.5^{\circ}$ to $4.5^{\circ} \mathrm{C}$ mean global temperature change for 2100 (IPCC 1990). In 2001, after tens of billions of dollars of investment in global-change research, the IPCC projected a $1.4^{\circ}$ to $5.8^{\circ} \mathrm{C}$ temperature change for 2100 (IPCC 2001). Even as the IPCC has become more certain that temperature will increase, the uncertainty associated with its projections has also increased. Why? Researchers have concluded that there are many more scenarios of possible population and energy use than originally assumed and have learned that the global oceanatmosphere-biosphere system is much more complex than was once thought (IPCC 2001). Ignorance is bliss because it is accompanied by a lack of uncertainty.

The promise of prediction is that the range of possible futures might be narrowed in order to support (and indeed to some degree determine) decision making. By way of contrast, in his Foundation series, science fiction writer Isaac Asimov introduced the notion of "psychohistory." Asimov's psychohistorians had the ability to predict the future with certainty based on complex mathematical models. We know that Asimov's characters lie squarely in the realm of science fiction - there can be no psychohistory such as this. The future, to some degree, will always be clouded. But, experience shows that this cloudiness is variable; we can predict some events with skill, and the promise of prediction can be realized. Understanding, using, and producing predictions depends upon understanding their uncertainty. What is it that leads to the uncertainty of earth and environmental predictions? What are the prospects of knowing the uncertainty of specific predictions?

A simple example might prove useful. Consider the poker game known as five-card draw. In a standard fifty-two-card deck, there are 2,598,960 possible five-card poker hands (Scarne 1986). Let us assume that in your hand you hold a pair. What are the chances that by exchanging the other three cards you will draw a third card to match the pair? In this instance you can know with great precision that in $71.428 \ldots \%$ of such situations you will fail to improve your hand. Thus, when you exchange three cards you are "uncertain" about the outcome that will result, but you can quantify that uncertainty with great certainty.

This sort of uncertainty is that associated with random processes, that is, one in which each element of a set (in this case a deck of cards) has an equal chance of occurring. Because we know the composition of the deck and the set of possible events (i.e., the relative value of dealt hands), it is possible to calculate precisely the uncertainty associated with future events. Scientists call this aleatory uncertainty, and it is studied using mathematical statistics (Hoffman and 
Hammonds 1994, Stewart 2000). Such uncertainty, by definition, cannot be reduced. One can never divine what the next card will be, although one can precisely calculate what one's chances are of receiving a particular card. Similarly, in predictions associated with the earth and environmental sciences there is also irreducible uncertainty associated with the nature of random processes.

Let us take the poker example a step further. Assume that you find yourself playing cards with a less-than-honest dealer. This dealer is adding and removing cards from the deck so that the deck no longer has the standard fifty-two cards. The process is no longer stationary - it is changing over time. If you were to know the cards added and removed, that is, to have the ability to quantify the changing composition of the deck, to quantify uncertainty, you would simply need to recalculate the probabilities based on the new deck of cards. However, if you were unaware that the deck was changing in its composition, then you could easily miscalculate the uncertainty associated with your options. Similarly, if you were aware that the deck was changing but were not privy to the exact changes, you would be unable to calculate precisely the uncertainty (but would know that the assumption of a standard fifty-two-card deck could be wrong). This sort of uncertainty is called epistemic uncertainty and is associated with incomplete knowledge of a phenomenon - and incomplete knowledge of the limits of one's knowledge (Hoffman and Hammonds 1994; Stewart 2000).

Unlike aleatory uncertainty, epistemic uncertainty can be reduced in some cases through obtaining improved knowledge. In the case of the changing deck of cards, uncertainty could be reduced using several methods. For instance, one could carefully observe the outcomes of a large number of hands and record the actual frequencies with which particular hands occur. For instance, if four aces were added to the deck, one would expect to be able to observe the results in the form of more hands with ace combinations. Of course, the more subtle the change, the more difficult it is to detect. ${ }^{5}$ The more one understands about the card replacement process, the better understanding one can have about the associated uncertainties. Unless one could discover the pattern underlying the change process (in effect "close" the system, Oreskes et al. 1994), then such theories would be subject to continuous revision as experience unfolds.

But even though epistemic uncertainty can in principle be reduced, if one is dealing with open systems (as is almost always the case for environmental predictions), the level of uncertainty itself can never be known with absolute certainty. Seismologists assigned a probability of $90 \%$ to their 1988 prediction of the Parkfield earthquake, but the earthquake never occurred (Savage 1991, Nigg 2000). Were the scientists simply confounded by the unlikely but statistically explicable one-out-of-ten chance of no earthquake? Or, was it because their probability calculation was simply wrong - that is, because the uncertainty associated with the prediction was in fact huge? Similarly, regardless of the sophistication of global climate models, many types of unpredictable events (volcanic eruptions that cool the atmosphere; new energy technologies that reduce carbon emissions) can render today's climate predictions invalid and associated uncertainties meaningless (see, e.g., Keepin 1986). 
A central theme that emerges from experience is that important decisions are often clouded by inherent uncertainty, and in many instances, efforts to reduce uncertainty can paradoxically have the opposite effect (Pielke 2001). ${ }^{6}$ Frequently, research results in discovery that the vast complexities associated with phenomena that evolve slowly over long periods-like those associated with the integrated earth system - were in fact previously underestimated, thereby having the effect of expanding uncertainties (Sarewitz et al. 2000). In a decision setting, this can have the perverse effect of increasing political controversy rather than reducing it, leading to calls for even more research to reduce uncertainties, while the problem goes unaddressed. No case illustrates this better than global climate change (Sarewitz and Pielke 2000).

One of the most critical issues in using models to develop information for decision making is to understand uncertainty - its sources, and its potential reducibility, as Weber (1999, 43, emphasis) observes:

If uncertainty is measurable and controllable, then forecasting and information management systems serve a high value in reducing uncertainty and in producing a stable environment for organizations. If uncertainty is not measurable and controllable, then forecasting and predictions have limited value and need to be understood in such context. In short, how we view and understand uncertainty will determine how we make decisions.

Thus, a lesson for any effort that seeks to model open systems to inform decision making, particularly through prediction, is that it is imperative to understand uncertainty, including its sources, potential irreducibility, and relevant experience, in the context of the decision making process. In some cases, such an effort may very well lead to the conclusion that decision making should turn to alternatives to prediction (e.g., examples would include robust strategies insensitive to uncertainties such as trial and error; see e.g., Brunner 2000; Herrick and Sarewitz 2000).

\section{Communicating Uncertainty}

Experience shows that neither the scientific community nor decision makers have a good record at understanding uncertainty associated with predictions (Sarewitz et al. 2000). Such understanding is necessary because "the decision making process is best served when uncertainty is communicated as precisely as possible, but no more precisely than warranted" (Budescu and Wallsten 1987, 78). But even in cases where uncertainty is well-understood, as is typically the case in weather forecasting, scientists face challenges in communicating the entirety of their knowledge of uncertainty to decision makers. Often, experts place blame for this lack of communication on the perceived lack of 
public ability to understand probabilistic information. The resulting policy prescription is for increased public education to increase scientific literacy (e.g., Augustine 1998; Rand 1998; Gibbs and Fox 1999). While improved scientific literacy has value, it is not the solution to improving communication of information about uncertainty.

Consider the following analogy. You wish to teach a friend how to play the game of tennis. You carefully and accurately describe the rules of tennis to your friend, but you speak in Latin to your English-speaking friend. When you get onto the court, your friend fails to observe the rules that you so carefully described. Following the game, it would surely be inappropriate to criticize your friend as incapable of understanding tennis and futile to recommend additional tennis instruction in Latin. But, this is exactly the sort of dynamic observed in studies of public understanding of scientific uncertainties. For example, Murphy et al. (1980) document that when weather forecasters call for, say, a 70\% chance of rain, decision makers understood the probabilistic element of the forecast but did not know whether rain has a $70 \%$ chance for each point in the forecast area, or that $70 \%$ of the area would receive rain with a $100 \%$ probability, and so on. ${ }^{7}$ Do you know?

The importance of understanding and communicating uncertainties associated with a prediction product was aptly illustrated in the case of the 1997 flooding of the Red River of the North (Pielke 1999). In February 1997, forecasters predicted that the river would see flooding greater than at any time in modern history. At Grand Forks, North Dakota, forecasters expected the spring flood to exceed the 1979 flood crest of 48.8 feet sometime in April. Forecasters issued a prediction that the flood would crest at 49 feet, hoping to convey the message that the flood would be the worst ever experienced. But the message sent by the forecasters was not the message received by decision makers in the community (cf. Fischoff 1994).

Decision makers in the community misinterpreted both the event being forecast and the uncertainty associated with the forecast. First, the prediction of 49 feet, rather than conveying concern to the public, instead resulted in reduced concern. Locals interpreted the forecast in the context of the previous record 1979 flood, which caused damage, but was not catastrophic. With the 1997 crest expected only a few inches higher than the record set in 1979, many expressed relief rather than concern, that is, "We survived that one OK, how much worse can a few inches be?" Second, decision makers did not understand the uncertainty associated with the forecast. Flood forecasts are extremely uncertain, especially forecasts of record floods for which there is no experience. Forecasters issued a quantitative forecast with a simple qualitative warning about uncertainty. Hence, many decision makers interpreted the forecast uncertainty in their own terms: Some viewed the forecast as a ceiling, that is, "the flood will not exceed 49 feet." Others viewed the forecast as uncertain and associated various uncertainties with the forecasts, ranging from 1 to 6 feet. The historical record showed that flood crest forecasts were, on average, off by about $10 \%$ of the forecast. 
On April 22, 1997, at Grand Forks the Red River crested at 54 feet, inundating the communities of Grand Forks, North Dakota, and East Grand Forks, Minnesota, and causing up to $\$ 2$ billion in damage (current dollars). In the aftermath of the flood, local, state, and national officials pointed to inaccurate flood forecasts as a cause of the disaster. With hindsight, a more reasoned assessment indicates that by any objective measure, the accuracy of the forecasts was not out of line with historical performance. Instead, decision makers and scientists failed to understand the meaning of the prediction both in terms of what was being forecast and the uncertainty associated with it.

A significant literature exists on communication of uncertain information, some based on experience in the sciences (e.g., Dow and Cutter 1998; Baker 2000; Glantz 2001) and much more (it seems) from the disciplines of communication, psychology, and sociology (Wallsten et al. 1986; Konold 1989; Hoffrage et al. 2000). The implications of this literature range from the straightforward: "statistics expressed as natural frequencies improve the statistical thinking of experts and nonexperts alike" (Hoffrage et al. 2000) to the more challenging: "probability expressions are interpreted differently by speakers and listeners" (Fillenbaum et al. 1991). However, it is clear that the substantial research on communication of uncertainty has not been well integrated with the research in the earth and environmental sciences that seeks to understand and describe uncertainties relevant to decision making. Understanding and communicating uncertainty by scientists and decision makers alike go hand-in-hand: both are necessary - but not sufficient - for information to contribute systematically to improved decisions.

\section{Understanding Predictability}

Consider again the poker example. With perfect knowledge of a card substitution process engineered by a less-than-honest dealer, one would be able to quantify completely and accurately the associated uncertainties in future hands. However, this situation is quite different from most cases that we find in the real world of modeling and prediction in the environmental sciences. In the real world, systems are open and there are fundamental limits to predictability. And, perhaps surprisingly, many scientific efforts to divine the future proceed without an adequate understanding of the limits to predictability. In addition to the aleatory and epistemic uncertainties discussed above, there are a number of other reasons for limits to predictability. Among these are sensitivity to initial conditions, complexity, and human agency.

First, predictability is limited because knowledge of the future depends upon knowing the present, which can never be completely or accurately characterized. For example, weather forecasts depend upon knowing the present state of the atmosphere and then projecting forward its future behavior, based on physical relationships represented in computer models. A result of the dependence on 
these "initial conditions" is that small changes in the initial conditions can subsequently lead to large differences in outcomes. Knowledge of initial conditions is obtained with instruments. In weather prediction, these can include balloons, radar, satellites, and other instruments that are subject to measurement errors. But even without such measurement errors, the simple act of rounding off a decimal can lead to vastly different outcomes. Popularized as the "butterfly effect," this is a fundamental characteristic of a chaotic system with limited predictability (Gleick 1987). Scientists have established 10-14 days as the limit of predictability for weather forecasts. In many other contexts the same limits hold but are not as well understood. Meteorologists run models repeatedly with small variations in input data (and sometimes in the model itself) to begin to understand the sensitivities of model output to initial conditions (e.g., Krishnamurti et al. 1999).

A second factor is that in the environmental sciences, phenomena of interest to policy makers are often incredibly complex and can result from interconnected human and earth processes. Consider nuclear waste disposal (Metlay, 2000). Predicting the performance of a waste facility 10,000 years into the future depends upon knowing, among a multitude of other potentially relevant factors, what sorts of precipitation might be expected at the site. Precipitation is a function of global climate patterns. In addition, global climate patterns might be sensitive to human processes such as energy and land use. Energy and land use are functions of politics, policy, social changes, and so on. What at first seems a narrow scientific question rapidly spirals into great complexity. One characterization of the concept holds that "a complex system is one whose evolution is very sensitive to initial conditions or to small perturbations, one in which the number of independent interacting components is large, or one in which there are multiple pathways by which the system can evolve" (Whitesides and Ismagilov 1999). Scientists are just beginning to understand the implications of complexity for prediction (see Waldrop 1992).

A third factor is the role of human agency. In situations where human decisions are critical factors in the evolution of the future being predicted (that is to say, almost every issue of environmental policy), the aggregate record of prediction is poor. Ascher (1981) argues that "unless forecasters are completely ignorant of the performance record, or are attracted solely by the promotional advantages of the scientific aura of modeling, they can only be attracted to benefits not yet realized." The poor performance of predictions of societal outcomes is consistent across diverse areas that include energy demand (Keepin 1986), energy supplies (Gautier 2000), population (Cohen 1996), elections (Mnookin 2001), corporate financial performance (Dreman and Berry 1994), macro-economics (CBO 1999), and medicine (Fox et al. 1999). To the extent that modeled outcomes depend upon some degree of accuracy in predicting factors such as these, predictability clearly will be limited.

And yet, effective decision making cannot occur without some way to anticipate the consequences of alternative courses of action. There is a considerable range of cases in which prediction and modeling contributed to effective 
decisions. The practice of insurance and engineering would not be possible without predictive ability. And more relevant to present purposes, the apparently successful response to stratospheric ozone depletion would not have been possible without predictive and diagnostic modeling (Pielke and Betsill 1997). But understanding (and indeed creating) those situations where prediction and modeling serve effective decision making is not straightforward, if simply because questions about the roles of models and prediction in decision making are rarely asked, much less answered.

\section{What Is a "Good" Model?}

This section focuses on models as a means to produce predictions for decision making, as well as a social and scientific mechanism that fosters integration of knowledge. The "goodness" of predictions produced from models can be understood from two distinct perspectives: product and process.

\section{Prediction as Product}

The first and most common perspective is to view models simply as generators of an information product. Often, when a model is applied to decision problems, it is used to produce a prediction, that is, a "set of probabilities associated with a set of future events" (Fischoff 1994). To understand a prediction, one must understand the specific definition of the predicted event (or events), as well as the expected likelihood of the event's (or events') occurrence. From this perspective, the goal of modeling is simply to develop "good" predictions (Pielke et al. 1999). Three important considerations in the production of "good" predictions are accuracy, sophistication, and experience.

Accuracy. Accuracy is important because "on balance, accurate forecasts are more likely than inaccurate forecasts to improve the rationality of decision making" (Ascher 1979, 6). With a few exceptions, once a forecast is produced and used in decision making, few researchers or decision makers ever look back to assess its skill (Sarewitz et al. 2000). Measuring the skill of a prediction is not as straightforward as it might seem. Consider the case of early tornado forecasts. In the $1880 \mathrm{~s}$, a weather forecaster began issuing daily tornado forecasts in which he would predict for the day "tornado" or "no tornado." After a period of issuing forecasts, the forecaster found his forecasts to be $96.6 \%$ correct. But others who looked at the forecaster's performance discovered that simply issuing a standing forecast of "no tornadoes" would result in an accuracy rate of $98.2 \%$ ! This finding suggested that, in spite of the high degree of correct forecasts, the forecaster was providing predictions with little skill- defined as the improvement of a forecast over some naïve standard — and which could result in costs rather than benefits. Simply comparing a prediction with actual events does not provide enough information with which to evaluate its performance. A 
more sophisticated approach is needed. Thus, predictions should be evaluated in terms of their "skill," defined as the improvement provided by the prediction over a naïve forecast, such as that that would be used in the absence of the prediction. ${ }^{8}$

Sophistication. Decision makers sometimes are led to believe that sophistication of a prediction methodology lends itself to greater predictive skill, that is, given the complexity of the world a complex methodology should perform better. In reality, the situation is not so clear-cut. An evaluation of the performance of complex models has shown that "methodological sophistication contributes very little to the accuracy of forecasts" (Ascher 1981; see also Keepin 1986). A lesson for decision makers is that sophisticated prediction methodologies (or by extension the resources devoted to development of such methodologies) do not necessarily guarantee predictive, much less decision making, successes. Because complex models often require significant resources (computation, humans, etc.), a trade-off invariably results between producing one or a few realizations of a highly complex model and many runs of a simpler, less intensive version of the model. For instance, the U.S. National Assessment of Climate Change used only two scenarios of future climate due to computation limitations (NACC 2000). For many decision makers, having an ability to place modeled output into the context of the entire "model-output space" would have been more useful than the two products that were produced largely without context. This is an example of confusion between consolidative and exploratory modeling.

Experience. In weather forecasts, society has the best understanding of prediction as a product. Consider that in the United States the National Weather Service issues more than 10 million predictions every year to hundreds of millions of users. This provides a considerable basis of experience on which users can learn, through trial and error, to understand the meaning of the prediction products that they receive. Of course, room for confusion exists. People can fail to understand predictions for record events for which there is no experience, as in the Red River case, or even a routine event being forecast (e.g., 70\% chance of rain). But experience is essential for effective decision making, and most decision makers have little experience using models or their products. Erev et al. (1993) provide a useful analogy:

Consider professional golfers who play as if they combine information concerning distance and direction of the target, the weight of the ball, and the speed and direction of the wind. Now assume that we ask them to play in an artificial setting in which all the information they naturally combine in the field is reduced to numbers. It seems safe to say that the numerical representation of the information will not improve the golfer's performance. The more similar are the artificial conditions we create to the conditions with which the 
golfers are familiar, the better will be their performance. One can assume that decision making expertise, like golf expertise, is improved by experience, but not always generalized to new conditions.

The importance of experience does not necessarily limit the usefulness of models and their products in decision making, but it does underscore the importance of the decision context as a critical factor in using models (Stewart et al. 1997).

A range of experience illustrates that misunderstandings or misuse of prediction products have presented obstacles to decision makers' efforts to effectively use predictions. Considering the following:

- Global climate change (Rayner 2000). Debate has raged for more than a decade about the policy implications of possible future human-caused changes in climate. This debate has been about "global warming" expressed in terms of a single global average temperature. But global average temperature has no "real-world" meaning, and thus policy advocates have sought to interpret that "event" in different ways, ranging from pending global catastrophe to benign (and perhaps beneficial) change. The issue of uncertainty compounds the issue. As a result, predictive science has been selectively used and misused to justify and advance the existing objectives of participants in the process (Sarewitz and Pielke 2000).

- Asteroid impacts (Chapman 2000). In recent years, scientists have increased their ability to observe asteroids and comets that potentially threaten the earth. In this case, the "event" is clear enough - possible extinction of life on earth if a large asteroid slams into the earth - and its prediction seemingly straightforward, uncomplicated by human agency. But scientific overreaction to the discovery of 1997 XF11 and the associated prediction that it could strike the earth on October 26, 2028, illustrate that understandings of uncertainty are critical (Chapman 2000). In this case, hype might have damaged future credibility of scientists who study this threat.

These examples and others illustrate the difficulties associated with understanding prediction as a product (Sarewitz et al. 2000). At the same time, these cases also demonstrate that improving the use of prediction involves more than simply developing "better" predictions, whether more precise, for example, a forecast of a 49.1652 flood crest at East Grand Forks; more accurate, for example, a forecast of a 51 foot crest; or more robust, for example, a probabilistic distribution of various forecast crest levels. While better predictions are in many cases more desirable, better decisions require attention to the broader 
prediction process. From this standpoint, better predictions may be neither necessary nor sufficient for improved decision making and, hence, desired outcomes. For better decisions, it is necessary to understand prediction as a product in the context of a process.

\section{Prediction as Process}

A second perspective is to view modeling as part of a broader prediction process. Included are the participants, perspectives, institutions, values, resources, and other factors that together determine policies for the prediction enterprise, as well as how the prediction enterprise contributes to public demands for action or tools with respect to the issues that they bring to the attention of decision makers. From this perspective, the goal of the prediction enterprise is good decisions. Modeling, due to its (potentially) integrative nature, is an important element of the prediction process.

The successful use of predictions depends more upon a healthy process than just on "good" information (Sarewitz et al. 2000). Weather forecasts have demonstrably shown value not because they are by any means "perfect," but because users of those predictions have successfully incorporated them into their decision routines. The prediction process can be thought of as three parallel subprocesses (Sarewitz et al. 2000):

Research Process includes the fundamental science, observations, etc. as well as forecasters' judgments and the organizational structure which go into the production of predictions for decision makers.

Communication Process includes both the sending and receiving of information; a classic model of communication is: who, says what, to whom, how, and with what effect.

Choice Process

includes the incorporation of predictive information in decision making. Of course, decisions are typically contingent upon many factors other than predictions.

Often, some persons mistakenly ascribe a linear relation to the processes. Instead, they are better thought of as components of a broader prediction process, with each of the subprocesses taking place in parallel and with significant feedback and interrelations between them.

Peter Drucker has written an eloquent description of the modern organization that applies equally well to the prediction process. "Because the organization is composed of specialists, each with his or her own narrow knowledge area, its mission must be crystal clear . . . otherwise its members become confused. They will follow their specialty rather than applying it to the common 
task. They will each define 'results' in terms of that specialty, imposing their own values on the organization" (Drucker 1993, 54).

Drucker continues with an apt metaphor. "The prototype of the modern organization is the symphony orchestra. Each of 250 musicians in the orchestra is a specialist, and a high-grade one. Yet, by itself, the tuba doesn't make music; only the orchestra can do that. The orchestra performs only because all 250 musicians have the same score. They all subordinate their specialty to a common task" (Drucker 1993, 55).

In the process of modeling and prediction in support of decision making, success according to the criteria of any subset of the three subprocesses does not necessarily result in benefits to society. Consider the following examples.

- The case of the Red River floods presented earlier illustrates that a technically skillful forecast that is miscommunicated or misused can actually result in costs rather than benefits. The overall prediction process broke down in several places. No one in the research process fully understood the uncertainty associated with the forecast; hence little attention was paid to communication of uncertainty to decision makers. As a result, poor decisions were made and people suffered, probably unnecessarily. Given that Grand Forks will to some degree always depend upon flood predictions, the situation might be improved in the future by including local decision makers in the research process in order to develop more useful products (see Pielke 1999).

- In the case of earthquake prediction, a focus on developing skillful predictions of earthquakes in the Parkfield region of California brought together seismologists with local officials and emergency managers (Nigg 2000). A result was better communication among these groups and overall improved preparation for future earthquakes. In this case, even though the predictions themselves could not be shown to be skillful, the overall process worked because it identified alternatives to prediction that have led to decisions that are expected to reduce the impacts of future earthquakes in this region, such as improving building codes and enforcement, insurance practices, and engineering designs.

- The case of global climate change may be in the early stages of what was documented in the case of earthquakes (Rayner 2000). Policy making focused on prediction has run up against numerous political and technical obstacles. Meanwhile alternatives to prediction have become increasingly visible. The prediction process can be judged successful if the goal of climate policy-to reduce the impacts of future climate changes on environment and 
society - is addressed, independent of whether century-scale climate forecasts prove to be accurate (Sarewitz and Pielke 2000).

- The case of nuclear waste disposal has also evolved from one in which decision making focused first on developing skillful predictions to one in which decision making focused instead on actions that would be robust under various alternative futures (Metlay 2000). In this case, the policy problem of storing nuclear waste for a very long time (and associated uncertainties) was addressed via decision making by selecting an engineering design that was robust to a very wide range of uncertainties and not by selecting a design based on a specific prediction.

As Robinson $(1982,249)$ observes, "by basing present decisions on the apparent uncovering of future events, an appearance of inevitability is created that de-emphasizes the importance of present choice and further lessens the probability of developing creative policy in response to present problems ... [predictions] do not reveal the future but justify the subsequent creation of that future." The lesson for decision makers is that one is in most cases more likely to reduce uncertainties about the future through decision making rather than through prediction.

The criteria for evaluating the "goodness" of a model are thus directly related to the purposes for which a model is to be used. A consolidative model will most likely be evaluated based on the accuracy of its output, whereas an exploratory model could easily succeed even if its results are highly inaccurate (Bankes 1993). Similarly, a model designed to advance understanding should be evaluated by a different set of criteria than a model designed to provide reliable products useful in decision making. For society to realize the benefits of the resources invested in the science and technology of prediction, the entire process must function in a healthy manner, just like the sections of Drucker's orchestra must perform together to make music. Each subprocess of the broader prediction process must be considered in the context of the other subprocesses; they cannot be considered in isolation.

\section{Conclusion: For Better Decisions, Question Predictions}

The analytical vignettes presented in this paper begin to highlight some of the shared characteristics of healthy decision processes for the use of model products, particularly predictions. One characteristic is the critical importance of decision makers who have experience with the phenomena being predicted, as well as experience with the predictions themselves. The less frequent, less observable, less spatially discrete, more gradual, more distantly future, and more severe a predicted phenomenon, the more difficult it is to accumulate di- 
rect experience. Where direct societal experience is sparse or lacking, other sources of societal understanding must be developed or the prediction process will not function as effectively. Science alone and prediction in particular do not create this understanding.

More broadly, what is necessary above all is an institutional structure that brings together throughout the entire prediction process scientists with those who solicit and use predictions, so that each knows the needs and capabilities of the others. It is crucial that this process be open, participatory, and conducive to mutual respect. Efforts to shield expert research and decision making from public scrutiny and accountability invariably backfire, fueling distrust and counterproductive decisions.

While efforts to predict natural phenomena have become an important aspect of the earth and environmental sciences, the value of such efforts, as judged especially by their capacity to improve decision making and achieve policy goals, has been questioned by a number of constructive critics. The relationship between prediction and policy making is not straightforward for many reasons, among them:

- Accurate prediction of phenomena may not be necessary to respond effectively to political or socioeconomic problems created by the phenomena (for example, see Landsea et al. 1999).

- Phenomena or processes of direct concern to policy makers may not be easily predictable. Likewise, predictive research may reflect discipline-specific scientific perspectives that do not provide "answers" to policy problems, which are complex mixtures of facts and values and which are perceived differently by different policy makers (for example, see Herrick and Jamieson 1995).

- Necessary political action may be deferred in anticipation of predictive information that is not forthcoming in a time frame compatible with such action. Similarly, policy action may be delayed when scientific uncertainties associated with predictions become politically charged (in the issue of global climate change, for example; see Rayner and Malone 1998).

- Predictive information also may be subject to manipulation and misuse, either because the limitations and uncertainties associated with predictive models are not readily apparent, or because the models are applied in a climate of political controversy and high economic stakes.

- Emphasis on predictive products moves both financial and intellectual resources away from other types of research that might 
better help to guide decision making (for example, incremental or adaptive approaches to environmental management that require monitoring and assessment instead of prediction; see Lee 1993).

These considerations suggest that the usefulness of scientific prediction for policy making and the resolution of societal problems depends on relationships among several variables, such as the timescales under consideration, the scientific complexity of the phenomena being predicted, the political and economic context of the problem, and the availability of alternative scientific and political approaches to the problem.

In light of the likelihood of complex interplay among these variables, decision makers and scientists would benefit from criteria that would allow them to better judge the potential value of scientific prediction and predictive modeling for different types of political and social problems related to earth processes and the environment. Pielke et al. (1999) provide the following six guidelines for the effective use of prediction in decision making:

- Predictions must be generated primarily with the needs of the user in mind. And that user could be another scientist. For stakeholders to participate usefully in this process, they must work closely and persistently with the producers of predictions to communicate their needs and problems.

- Uncertainties must be clearly understood and articulated by scientists, so that users have a chance to understand their implications. Failure to understand uncertainties has contributed to poor decisions that then undermined relations among scientists and decision makers. But merely understanding the uncertainties does not mean that the predictions will be useful. If policy makers truly understood the uncertainties associated with predictions of, for example, global climate change, they might decide that strategies for action should not depend on predictions (Rayner and Malone 1998).

- Experience is a critically important factor in how decision makers understand and use predictions.

- Although experience is important and cannot be replaced, the prediction process can be facilitated in other ways, for example, by fully considering alternative approaches to prediction, such as robust policies insensitive to uncertainties. Indeed, alternatives to prediction must be evaluated as a part of the prediction process. 
- To ensure an open prediction process, stakeholders must question predictions. For this questioning to be effective, predictions should be as transparent as possible to the user. In particular, assumptions, model limitations, and weaknesses in input data should be forthrightly discussed. Even so, lack of experience means that many types of predictions will never be well understood by decision makers.

- Last, predictions themselves are events that cause impacts on society. The prediction process must include mechanisms for the various stakeholders to fully consider and plan what to do after a prediction is made.

When the prediction process is fostered by effective, participatory institutions, and when a healthy decision environment emerges from these institutions, the products of predictive science may become even less important. Earthquake prediction was once a policy priority; now it is considered technically infeasible, at least in the near future. But in California the close, institutionalized communication among scientists, engineers, state and local officials, and the private sector has led to considerable advances in earthquake preparedness and a much-decreased dependence on prediction. On the other hand, in the absence of an integrated and open decision environment, the scientific merit of predictions can be rendered politically irrelevant, as has been seen with nuclear waste disposal and acid rain. In short, if no adequate decision environment exists for dealing with an event or situation, a scientifically successful prediction may be no more useful than an unsuccessful one.

These recommendations fly in the face of much current practice where, typically, policy makers recognize a problem and decide to provide resources to science to reduce uncertainty or produce predictions. Scientists then go away and do research to predict natural behavior associated with the problem, and predictions are finally delivered to decision makers with the expectation that they will be both useful and well used. This sequence, which isolates prediction research but makes policy dependent on it, rarely functions well in practice.

Yet, once we have recognized the existence of a prediction enterprise, it becomes clear that prediction is more than a product of science. Rather, it is a complex process, one that includes all the interactions and feedbacks among participants, perspectives, institutions, values, interests, resources, decisions, and other factors that constitute the prediction enterprise. From this perspective, the goal of the prediction enterprise is good decisions, as evaluated by criteria of public benefit. The value of predictions for environmental decision making therefore emerges from the complex dynamics of the prediction process, and not simply from the technical efforts that generate the prediction product (which are themselves an integral part of the prediction process). All the same, it is the expectation of a useable prediction product that justifies the existence 
of the prediction enterprise. This expectation turns out to be extremely difficult to fulfill.

This chapter has presented only a few of the many considerations that must be understood if scientific modeling and prediction are indeed to fulfill public expectations of the contributions of science in addressing environmental policy problems. There is considerable need for debate and discussion, supported by rigorous knowledge, on the proper role of modeling and prediction in decision making, rather than a simple assumption of what that role should be. However, one clear implication of the considerations presented in this paper is that the belief that modeling and prediction can simultaneously meet the needs of both science and decision is untenable as currently practiced. For ecosystem science, there exists a body of experience in understanding, using, and producing predictions across the sciences on which to build, to the potential benefit of both research and policy.

Acknowledgements. Several sections of this chapter are closely related to two earlier publications: Sarewitz et al. (2000) and Pielke et al. (1999), both of which resulted from the project "Use and Misuse of Predictions in the Earth Sciences," sponsored by the National Science Foundation. I would like to acknowledge gratefully the significant contributions of my collaborators on the prediction project-Dan Sarewitz and Rad Byerly - to the mix of ideas and expressions from those collaborative publications that have found their way into this chapter. This chapter also has benefited a great deal from the comments and suggestions of Rich Conant, Bobbie Klein, Naomi Oreskes, and an anonymous reviewer. An earlier version was drafted in preparation for Cary Conference IX, "Understanding Ecosystems: The Role of Quantitative Models in Observations, Synthesis, and Prediction." Participation in an NSF-sponsored workshop on ecological forecasting (Clark et al. 2001) provided additional motivation for introducing some of the lessons from our prediction project to the ecological community. Of course, all responsibility for errors of fact or interpretation lies solely with the author.

\section{Notes:}

\footnotetext{
${ }^{1}$ Oreskes (pers. comm.) argues that no model of a natural system can ever be fully specified, and therefore cannot in principle meet the definition of a consolidative model.

${ }^{2}$ A consolidative model can be properly used in exploratory fashion, but the real threat to decision making occurs when the opposite occurs. For an extended treatment of such models see Bankes (1993).

${ }^{3}$ On the USGCRP, see Pielke 2000a and 2000b.

${ }^{4}$ On the interpretation of climate model results, see Trenberth 1997, Edwards 1999, IPCC 2001. On the media's presentation of climate research results, see Henderson-Sellers 1998. On their role in decision, see Sarewitz and Pielke 2000 and Sluijs et al. 1998.
} 


\footnotetext{
${ }^{5}$ In a very similar fashion, some studies of global climate change use such a method to assess whether the storms, temperature, precipitation, etc., of one period differ significantly from that of another period (e.g., Wunsch 1999).

${ }^{6} \mathrm{~A}$ related consideration is that attempts to eliminate uncertainty by changing thresholds for decision (e.g., changing the wind-speed criteria for hurricane evacuation) invariably result in trade-offs between false alarms and misses (i.e., type I and type II errors), with associated societal costs. See Stewart 2000.

${ }^{7}$ There is a considerable literature on the use of weather forecasts that supports this line of argument. See in particular the work of Murphy (e.g., Murphy et al. 1980) and Baker (e.g., Baker 2000).

${ }^{8}$ The term "skill" is jargon; however the notion of evaluating predictions against a naïve baseline is fundamental to the evaluation of weather forecasts and financial forecasts (such as mutual fund performance). For forecasts that are probabilistic, rather than categorical, the evaluation of skill can be somewhat more complicated, but adheres to the same principles. See Murphy 1997 for a technical discussion of the many dimensions of predictive skill. There are other dimensions of predictive "goodness" that are central to evaluation of its role in decision making -including comprehensibility, persuasiveness, usefulness, authoritativeness, provocative ness, importance, value, etc., for discussion, see Ascher 1979, Armstrong 1999 and Sarewitz et al. 2000.
}

\section{References}

Armstrong, J.S. 1999. Principles of Forecasting: A Handbook for Researchers and Practitioners. Netherlands: Kluwer Academic.

Ascher, W. 1979. Forecasting: An Appraisal for Policymakers. Baltimore: Johns Hopkins University Press.

. 1981. The forecasting potential of complex models. Policy Sciences 13: 247-267.

Augustine, N. 1998. What we don't know does hurt us. How scientific illiteracy hobbles society. Science 279: 1640-1641.

Ayala, F. 1996. The candle and the darkness. Science 273: 442.

Baker, E. J. 2000. Hurricane evacuation in the United States. Pp. 306-319 in R. Pielke Jr. and R. Pielke Sr., editors. Storms. London: Routledge Press.

Bankes, S. 1993. Exploratory modeling for policy analysis. Operations Research 41: 435-449.

Brunner, R. 2000. Alternative to prediction. Chapter 14 in D. Sarewitz, R.A. Pielke Jr., and R. Byerly, editors. Prediction: Science, Decision Making, and the Future of Nature. Washington, DC: Island Press.

Budescu, D.V., and T.S. Wallsten. 1987. Subjective estimation of precise and vague uncertainties. Pp. 63-81 in G. Wright and P. Ayton, editors. Judgmental Forecasting. Chinchester: Wiley.

CBO (Congressional Budget Office). 1999. Evaluating CBO's record of economic forecasts. ftp://ftp.cbo.gov/14xx/doc1486/fceval99.pdf.

CES (Committee on Earth Sciences). 1989. Our Changing Planet: A U.S. Strategy for Global Change Research. A report to accompany the U.S. President's fiscal year 1990 budget. Washington, DC: Office of Science and Technology Policy. 
Chapman, C. 2000. The asteroid/comet impact hazard: Homo sapiens as dinosaur? Chapter 6 in D. Sarewitz, R.A. Pielke Jr., and R. Byerly, editors. Prediction: Science, Decision Making, and the Future of Nature. Washington, DC: Island Press.

Clark, J.S., S.R. Carpenter, M. Barber, S. Collins, A. Dobson, J.A. Foley, D.M. Lodge, M. Pascual, R. Pielke Jr., W. Pizer, C. Pringle, W.V. Reid, K.A. Rose, O. Sala, W.H. Schlesinger, D.H. Wall, and D. Wear. 2001. Ecological forecasts: An emerging imperative. Science 293: 657-660.

Cohen, J. 1996. How Many People Can the Earth Support? New York: W.W. Norton.

Cullen. A., and M. Small. 2000. Uncertain risk: The role and limits of quantitative assessment. Manuscript.

Dow, K. and S.L. Cutter. 1998. Crying wolf: Repeat responses to hurricane evacuation orders. Coastal Management 26: 237-252.

Dreman, D.N., and M.A. Berry. 1994. Analyst forecasting errors and their implications for security analysts. Financial Analysts Journal. May/June, 3041.

Drucker, P. 1993. Post-capitalist Society. New York: Harper Collins.

Edwards, P. 1999. Global climate science, uncertainty, and politics: Data-laden models, model-filtered data. Science as Culture 8: 437-472.

Erev, I., G. Bornstein, and T.S. Wallsten. 1993. The negative effect of probability assessments on decision quality. Organizational Behavior and Human Decision Processes 55: 78-94.

Fillenbaum, S., T.S. Wallsten, B.L. Cohen, and J.A. Cox. 1991. Some effects of vocabulary and communication task on the understanding and use of vague probability expressions. American Journal of Psychology 104: 35-60.

Fischoff, B. 1994. What forecasts (seem to) mean. International Journal of Forecasting 10: 387-403.

Fox, E., K. Landrum-McNiff, Z. Zhong, N.V. Dawson, A.W. Wu, and J. Lynn. 1999. Evaluation of prognostic criteria for determining hospice eligibility in patients with advanced lung, heart, or liver disease. Journal of the American Medical Association 282: 1638-1645.

Gautier, D. 2000. Oil and gas resource appraisal: Diminishing reserves, increasing supplies. Chapter 11 in D. Sarwitz, R.A. Pielke Jr., and R. Byerly, editors. Prediction: Science, Decision Making, and the Future of Nature. Washington, DC: Island Press.

Gibbs, W.W. and D. Fox. 1999. The false crisis of science education. Scientific American. 1 October, 86-93.

Glantz, M.H. 2001. Currents of Change: El Niño and La Niña Impacts on Climate and Society. 2nd ed. Cambridge: Cambridge University Press.

Gleick, J. 1987. Chaos: Making a New Science. New York: Penguin Books.

Henderson-Sellers, A. 1998. Climate whispers: Media communication about climate change. Climatic Change 4: 421-456. 
Herrick, C., and D. Jamieson. 1995. The social construction of acid rain: Some implications for science/policy assessment. Global Environmental Change 5: 105-112.

Herrick, C., and D. Sarewitz. 2000. Ex post evaluation: A more effective role for scientific assessments in environmental policy. Science, Technology, and Human Values 25: 309-331.

Hoffman, F.O., and J.S. Hammonds. 1994. Propagation of uncertainty in risk assessments: The need to distinguish between uncertainty due to lack of knowledge and uncertainty due to variability. Risk Analysis 14: 707-712.

Hoffrage, U., S. Lindsey, R. Hertwig, G. Gigerenzer. 2000. Communicating statistical information. Science 290: 2261-2262.

IPCC (Intergovernmental Panel on Climate Change). 1990. Climate Change: The IPCC Scientific Assessment. Cambridge: Cambridge University Press.

- 2001. Climate Change 2001: The Scientific Basis. Cambridge: Cambridge University Press.

Keepin, B. 1986. Review of global energy and carbon dioxide projections. Annual Review of Energy 11: 357-392.

Konold, Clifford. 1989. Informal conceptions of probability. Cognition and Instruction 6(1): 59-98.

Krishnamurti, T.N., C.M. Kishtawal, T. LaRow, D. Bachiochi, Z. Zhang, C.E. Williford, S. Gadgil, and S. Surendran. 1999. Improved skills for weather and seasonal climate forecasts from multi-model superensemble. Science 285: 1548-1550.

Landsea, C.L., R.A. Pielke Jr., A. Mestas-Nuñez, and J. Knaff, 1999. Atlantic Basin hurricanes: Indices of climate changes. Climate Change 42: 9-129.

Lasswell, H.D., and A. Kaplan. 1950. Power and Society. New Haven: Yale University Press.

Lee, K. 1993. Compass and Gyroscope: Integrating Science and Politics for the Environment. Washington, DC: Island Press.

Metlay, D. 2000. From tin roof to torn wet blanket: Predicting and observing groundwater movement at a proposed nuclear waste site. Chapter 10 in D. Sarewitz, R.A. Pielke Jr., and R. Byerly, editors. Prediction: Science, Decision Making, and the Future of Nature. Washington, DC: Island Press.

Mnookin, S. 2001. It happened one night. Brill's Content 4(1): 94-96.

Morrison, M. and M.S. Morgan 1999. Models as mediating instruments. Pp. 10-37 in M.S. Morgan and M. Morrison, editors. Models as Mediators: Perspectives on Natural and Social Science. Cambridge: Cambridge University Press.

Murphy, A.H. 1997. Forecast verification. Pp. 19-74 in R. Katz and A. Murphy, editors. Economic Value of Weather and Climate Forecasts. Cambridge: Cambridge University Press.

Murphy, A.H., S. Lichtenstein, B. Fischoff, and R.L. Winkler. 1980. Misinterpretations of precipitation probability forecasts. Bulletin of the American Meteorological Society 61: 695-701. 
NACC (National Assessment on Climate Change). 2000. Climate Change Impacts on the United States, National Assessment Synthesis Team. U.S. Global Change Research Program. Cambridge: Cambridge University Press.

Nigg, J. 2000. Predicting earthquakes: Science, pseudoscience and public policy paradox. Chapter 7 in D. Sarewitz, R A. Pielke Jr., and R. Byerly, editors. Prediction: Science, Decision Making, and the Future of Nature. Washington, DC: Island Press.

Oreskes, N., K. Shrader-Frechette, and K. Belitz. 1994. Verification, validation, and confirmation of numerical models in the earth sciences. Science 263: 641-646.

Pielke, Jr. R.A. 1999. Who decides? Forecasts and responsibilities in the 1997 Red River floods. Applied Behavioral Science Review 7: 83-101.

2000a. Policy history of the U.S. Global Change Research Program. Part I. Administrative development. Global Environmental Change 10: 925.

. 2000b. Policy history of the U.S. Global Change Research Program. Part II. Legislative process. Global Environmental Change 10: 133-144.

. 2001. Room for doubt. Nature 410: 151.

Pielke Jr., R.A., and M.M. Betsill. 1997. Policy for science for policy: Ozone depletion and acid rain revisited. Research Policy 26: 157-168.

Pielke Jr. R.A., D. Sarewitz, R. Byerly, and D. Jamieson. 1999. Prediction in the earth sciences: Use and misuse in policy making. EOS: Transactions of the American Geophysical Society 80: 9.

Rand, H. 1998. Science, non-science and nonsense: Communicating with the lay public. Vital Speeches of the Day 64 (9): 282-284.

Rayner, S. 2000. Prediction and other approaches to climate change policy. Chapter 13 in D. Sarewitz, R.A. Pielke Jr., and R. Byerly, editors. Prediction: Science, Decision Making, and the Future of Nature. Washington, DC: Island Press.

Rayner, S., and E.L. Malone, editors. 1998. Human Choice and Climate Change. Columbus: Battelle Press.

Robinson, J.B. 1982. Backing into the future: on the methodological and institutional biases embedded in energy supply and demand forecasting. Technological Forecasting and Social Change 21: 229-240.

Sarewitz, D., and R.A. Pielke Jr. 1999. Prediction in science and policy. Technology in Society 21: 121-133.

- 2000. Breaking the Global Warming Gridlock. Atlantic Monthly. 1 July, 55-64.

Sarewitz, D., R.A. Pielke Jr., and R. Byerly. 2000. Prediction: Science, Decision Making, and the Future of Nature. Washington, DC: Island Press.

Savage, J.C. 1991. Criticism of some forecasts of the National Earthquake Prediction Evaluation Council. Bulletin of the Seismological Society of America 81: 862-881.

Scarne, J. 1986. Scarne's New Complete Guide to Gambling. New York: Simon and Schuster. 
Sluijs, J.P. van der, J.C.M. van Eijnhoven, B. Wynne, S. Shackley. 1998. Anchoring devices in science for policy: The case of consensus around climate sensitivity. Social Studies of Science 28: 291-323.

Skidelsky, R. 2000. Skidelsky on Keynes. The Economist. November 25, 8385.

Stewart, T. 2000. Uncertainty, judgment and error in prediction. Chapter 3 in D. Sarewitz, R.A. Pielke Jr., and R. Byerly, editors. Prediction: Science, Decision Making, and the Future of Nature. Washington, DC: Island Press.

Stewart, T.R., P.J. Roebber, and L.F. Bosart. 1997. The importance of the task in analyzing expert judgment. Organizational Behavior and Human Decision Processes 69: 205-219.

Trenberth, K. 1997. The use and abuse of climate models. Nature 386: 131133.

Waldrop, M.M. 1992. Complexity: The Emerging Science at the Edge of Order and Chaos. New York: Simon and Schuster.

Wallsten, T.S., D.V. Budescu, A. Rapoport, R. Zwick, and B. Forsyth. 1986. Measuring the vague meanings of probability terms. Journal of Experimental Psychology 115(4): 348-365.

Weber, J. 1999. A response to public administration's lack of a general theory of uncertainty: A theoretical vision of uncertainty. Public Administration Review 23: 18-45.

Whitesides, G.F., and R.F. Ismagilov. 1999. Complexity in chemistry. Science 284: 289-292.

Wunsch, C. 1999. The interpretation of short climatic records with comments on the North Atlantic and Southern Oscillations. Bulletin of the American Meteorological Society 80: 245-256. 



\section{Part II}

Evaluating Ecosystem Models 